\title{
Journal of International Affairs
}

Vol. 3, 180-193, 2020

Doi: https://doi.org/10.3126/joia.v3i1.29094

Department of International Relations and Diplomacy

Tribhuvan University, Kathmandu, Nepal

Diplomatic Language: An Analysis of Salutations from Speeches used in International

\section{Diplomacy}

Surendra Pokhrel

\begin{abstract}
This paper analyzes the core aspects of diplomatic salutations through the discussion of speeches used at international summits. Speeches by heads of states were chosen from two NonAligned Movement (NAM) Summits (1989, 2005), South Summit of Group 77 and China (2005), Islamic-American Summit (2017) and Brazil, Russia, India, China, South Africa (BRICS) Summit (2018). Examining the context of salutations from the summits mentioned above, this paper aims to provide some insight into the international diplomatic protocol of salutations as applied at international gatherings. Research findings suggest that most leaders use salutations in a way that reflects their position within the political and cultural systems of their respective countries.
\end{abstract}

Keywords: Diplomacy, Diplomatic Language, International Relations, Salutations. 


\section{Introduction}

Diplomacy is the art of pursuing one's country's national interest vis-à-vis other countries. In a recent article, Vincent Pouliot \& Jeremie Cornut (2015: 299) define diplomacy as "a label that practitioners use in order to describe an array of socially organized and meaningful ways of doing things on the international stage". Diplomacy is mediation carried out between two different entities, implying the application of tactics and intelligence to further the conduct of official relations that are mutually beneficial. Bilateral and multilateral forums are regarded as a soft and effective way of pursuing diplomatic goals. These gatherings help countries to cultivate their image in the international arena but might also help to spread propaganda. One key element of diplomacy is often, though not always, to minimize misunderstandings and conflicts of interest through negotiations, hopefully creating a mutual understanding. While traditional diplomacy focused on governments, globalization, and an ever-growing interdependence among states means that today's diplomacy is not only related to Foreign Ministries but often involves relations between states and non-state bodies, a type of relationship Geoffrey Wiseman (1999: 15) has branded "polylateralism”.

Effective diplomacy should be synchronized with foreign policy to promote the interests of the political entity concerned in the international arena. In order to attribute positive outcomes in diplomacy, multiple factors should be taken into consideration, such as the place and timing of diplomatic discussions, and the political atmosphere surrounding the venues of these gatherings. Even though the language used by diplomats at times of negotiations might differ depending on their particular political objective, the careful choosing of appropriate words is nevertheless vital for the success of such consultations. Zhang $\mathrm{Na}$, the author of $A n$ Analysis of Vagueness on Diplomatic Language (2012: 1-5) characterizes diplomatic language as exhibiting various distinctive linguistic features such as ambiguity, euphemism, implicitness, and vagueness.

Diplomatic language is a social dialect meant to further the successful pursuit of political interests and is mostly used by individuals employed in a diplomatic capacity. Though often characterized as being subtle, it is a subtlety that is frequently arising out of the complexities of working in or with other cultures differing from that of the diplomatic agent. Consequently, it seems to be evident that efficient use of diplomatic language demands that its practitioners be interculturally competent enough to understand the core values of the culture(s) they work in or with. Cultural differences may be seen in, for example, the salutations, which are an essential part of diplomatic language and help the speaker to create a positive atmosphere 
among the audience.

Frequent bilateral and multilateral meetings enable nation-states and other political entities to pursue their political interests in the international arena with other state and non-state actors of importance. Every year, thousands of such meetings, whether intra-governmental, state-sponsored or funded by private entities, or primarily involving non-state actors, are held throughout the world. International summits, conferences, forums, or conventions are places where negotiations are conducted, discussions take place, and deals are made, albeit often behind the scenes rather than in public. Frequently, diplomats and politicians are negotiating the details behind the scene before such events so that either treaties or at least joint statements can be concluded on stage. Muhammad Azizan \& Nornandia Zakaria (2018: 109) distinguish summits from conferences and conventions on the basis that summits are reserved for heads of state, dignitaries, and top-level executives. At conferences and conventions, high-level executives or representatives of the said political entities intermingle with academics, experts, professionals etc. Though names and topics may differ, such forums, summits, conferences, or conventions all carry some kind of significance within international relations.

At high-profile diplomatic gatherings, such as the annual summit of Association of Southeast Asian Nations (ASEAN), the annual session of General Assembly of United Nations (UN), or the G7/8 or the G20 summits, multilateral forums such as Munich Security Conference (MSC), United Nations Climate Change Conferences, or World Economic Forum (WEF) in Davos (Switzerland), it is common for the opening or closing sessions to consist of addresses from prominent politicians and experts on topics of general concern such as terrorism, climate change, or trade disputes. Such speeches are directed at an audience often consisting of highranking dignitaries, further adding significance to these addresses. There are various possible framing devices that are used to present and position the agendas of the speaker's country or organization relative to the audience. One way of creating a feeling of harmony is by employing salutations or opening greetings according to the diplomatic protocol.

Since there is little research available that deal directly with the topic of diplomatic salutations, this paper should be considered as a mere preliminary attempt, which will inevitably be superseded in the future. Its primary focus is to analyse certain salutations used in some speeches delivered at four international summits, namely the Non-Aligned Movement's Belgrade summit of 1989 and its Teheran summit of 2005, the Arab-Islamic summit of 2017, and the BRICS summit of 2018. Although the number of scrutinized salutations is limited, the examination results suggest some valuable aspects for further 
research in this field.

\section{Literature survey}

There can be little doubt that language sets the fundamental framework of diplomacy. Former Swiss diplomat Benoit Girardin (2001) elucidates the possibility for words to be manipulated by the speaker depending on the receiver's intention. Thus, diplomatic dialect is subject to adjustments so that both parties involved can endorse the outcome of a dialogue positively.

Diplomats such as Stanko Nick (2001) from Croatia and Aldo Matteucci (2001) from Switzerland, along with a French linguist, Edmond Pascual (2001), focus on the use of pragmatics in diplomacy, while researchers such as Zhang (2012) explicitly describe the distinctive linguistic features of diplomatic language. Prominent researchers on cultural competence, such as Daniel J. Kealey (1996, 2004), have conducted significant, multidimensional research on cross-cultural effectiveness in international diplomacy. Kealey, Dough MacDonald \& Thomas Vulpe (2004) explain how cultural competence can positively impact the negotiation process.

Former Foreign Minister of Jordan Kamel Abu Jaber (2001) also provides insight into the connection between culture and diplomatic language, arguing that the language of diplomacy should be neutral, rather than culture bound. Salutations allow, at least in part, a personal approach to their referent and can also reflect the individual speaker's personality. Researchers Robert M. Krauss \& Chi-Yue Chiu (1998) have found that people's attitudes affect ways of speaking. They also mention that gestures are also communicative devices, which amplify the information in the accompanying speech. Nearly 50 years ago, a Norwegian psychologist, Rangar Rommetveit (1974), had already investigated the interdisciplinary nature of human communication. For him, communication is best described as a conjunction of factors taken from psychology, linguistics, and literary competence.

A Dutch public opinion specialist, Dirk Heerwegh (2005), states that personalized greetings make recipients feel not only more respected, but also more valued, thus increasing significantly the chance of compliance with whatever request might be made. Hearing personalized names, according to research done by Dennis P. Carmody and Michael Lewis (2006), increases the brain activity associated with social behavior and long-term memory, which creates a sense of positivity. Personalized names with greetings naturally increase the dimension of attachment among individuals. The same applies during diplomatic negotiations. 


\section{Methodology}

This paper is part of a broader project dealing with various aspects of diplomatic speech, including greetings (salutations), praise, the body or main content, and the closing statement. In this short article, only the opening salutations of a limited number of summits are scrutinized. The five addresses selected for analysis represent a wide range of speakers and target audiences, varying from secular democratic Western nations, such as U.S.A., to conservative authoritarian Arab states, such as Qatar. The analyzed speeches were given between 1989 and 2018, thus offering a 20-year time frame, allowing one to look for possible changes in salutation patterns from the early post-Cold War times to the current era of "Twitter politics." The analysis offered here has been cross checked with the assistance of Dr. Christian W. Spang, a professor at the Graduate School of Foreign Studies of Daito Bunka University, Tokyo, Japan. Also reflected in my analysis are some aspects discussed with Pradip Kumar Gyawali, the current foreign minister of Nepal, in an interview granted to the author on 17 March 2019.

\section{Culture, Manners and Diplomatic Communication}

Depending on the resources devoted to diplomacy in their respective countries, diplomats receive various levels of instruction in the local language and culture of the foreign country in which they are to be stationed. It is a fact that not only career foreign service officers conduct international negotiations but also politicians. Many of the latter may not have an adequate background of the necessary intercultural competency to adequately deal with other countries. Global discourse, however, requires not only the existence of some cultural sensitivity, but also that it be proactively applied. Malaysian Scholar of International Relations Hafriza Burhanudeen (2006: 39) states that the commonality in diplomatic discourse can only be achieved through conscious choice of one's words. This can only be secured by established standards having become widespread, at least on the regional level, among the world's diplomatic community.

For international summits, conformity with international norms of communication is commonly secured by the fact that the speeches of world leaders are typically written by linguistically and culturally trained foreign service experts. The advantage of this standard practice is that it helps to preserve certain civility in international discourse. The disadvantage of diplomatic speechwriting is that the audience might not learn much about the real opinion of the individual leader delivering the address in question. 
In addition to culture, religion also plays an essential role in what people say and how they try to get their opinion across. The religion of the speaker(s) or addressee(s) also may dictate acceptable greetings or opening phrases. For instance, followers of the Islamic faith often use "salaam" or "Wa-Alaikum-Salaam," (وعليكم السلام), while adherents of Hinduism

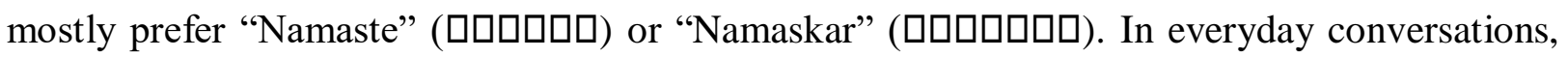
secular Western greetings such as "Good Morning/Afternoon/Evening" or similar phrases like "bonjour” (French), "Guten Tag” (German), or "Buenos días!" (Spanish) are common. As this style of greeting is secular, it is widely accepted where English, French, German, or Spanish are used as a lingua franca. Especially where greetings might be religiously based, secular salutations provide a neutral means to avoid identifying oneself with some potentially troublesome aspect of a specific cultural tradition without offending people with other cultural and/or religious backgrounds.

In an interview about the question of salutations with the author, Honorable Foreign Minister of Nepal Pradip Kumar Gyawali said, "In diplomacy, courtesy plays a crucial role in terms of personal relations and approach. If we greet one another in a personalized style, it brings us closer and helps to create an atmosphere of modesty. Also, this shows the uniqueness of the culture that you represent, thus implying many things, symbolically."

Respecting other cultures along with the established values of those cultures, without denying one's own, is essential for creating a sense of cordial relationship in diplomatic discourse. Being culturally sensitive is of utmost importance, especially when discourse might potentially be influenced by religiously generated norms. The religions are rarely monolithic and are often faction-ridden, making it difficult for an outsider to avoid potentially dangerous blunders. Inside one religious/cultural community, there may be followers of different faiths. For example, among Muslims, there are variations in salutations among Shia and Sunnis.

Though negotiations are frequently used to end or avoid wars, a few disrespectful words at the wrong time have sometimes been enough to derail already accomplished improvements. Diplomatic language must, therefore, maintain a high level of proficiency, both in written and spoken forms. Because of these and other potential stumbling stones, one might expect neutral salutations in diplomatic communication.

One should not forget the aspect of communication and its application of diplomatic language. Distinguished communication scholars John W. Bowers and Bradac J. James (1984: 872-874) describe communication as being a "generation of meaning" from spoken words, in a process "ubiquitous and powerful." Moreover, people exhibit different styles of behavior when 
they communicate, either by being explicit or implicit. Brazilian Linguist Francisco Gomes de Matos (2004: 281-83) claims that people can communicate by hedging, by not coming to the point, and also by (deliberate) vagueness, including through the use of generic terms as opposed to more specific expressions. For example, some leaders prefer not to use the name of a fellow leader, but instead refer to that individual by the title of that individual's official position.

By applying a "pedagogy of positiveness" to diplomatic communication, Gomes de Matos (2004: 283-84) emphasizes four critical aspects of language that diplomats need to weigh carefully: (1) being careful about "what to say"; (2) identifying (and avoiding) potentially aggressive, insensitive, offensive and destructive language; (3) using language as a tool for peacebuilding, peace-promoting, and peace-making; and (4) treating others with respect by being communicatively friendly. The points made by Gomes de Matos about the pursuit of diplomacy can be seen as grounded in the more general conversational maxims of "quantity, quality, relation and manner" proposed by British philosopher of language Paul Grice (1975: 45-47), whereby "one tries to be as informative as one possibly can, and gives as much information as is needed, one tries to be truthful and does not give information that is false or that is not supported by evidence. Furthermore, one tries to be relevant and says things that are pertinent to the discussion, when one tries to be as clear, as brief, and as orderly as one can in what one says, and where one avoids obscurity and ambiguity".

Olivier Arifon (2010: 71), a French researcher of coherence and efficiency in diplomacy, notes that diplomatic language may be simultaneously directed at different audiences for different purposes: the "language of diplomacy has both an internal dimension (between diplomats) and an external dimension (for the public and the media)". Traditionally, diplomacy focused on relationship-building between representatives of different states or non-state actors and it was generally rare for the public to gain any in-depth knowledge of closed-door discussions among diplomats. However, partly as a result of the instantaneous nature of electronic mass media communication, and the interactive nature of social media, international diplomacy is increasingly and consciously directed at a public that can act not only as an immediate independent observer, but, sometimes, even as an active participant. Many international forums are broadcast publicly via television, live feed, etc. Therefore, the (potential) audiences of such gatherings comprise not only the attendees in person, but also, more broadly, the general public experiencing it through some live or unfiltered feed. When one addresses such an international event, one should bear in mind that members of the public are watching them from every corner of the world. The message needs to be adequately addressed to that broader audience too. This places an even more significant burden on the speaker to 
avoid language that could be seen as provocative, offensive or humiliating by some part of this wider audience.

\section{Case studies}

Speeches at international summits usually contain four main sections: (1) The opening salutation, greetings, (2) an expression of appreciation or admiration for the host nation or organization, (3) discussion about the issues of concern, and (4) a closing section. The speeches chosen here are extracted from the official government websites of the respective countries represented, except for the speech of Emir of Qatar, which was taken from the G77 website. The four speeches mentioned can be found in English. In three of the five cases discussed below, it is not clear whether these speeches were translated from some original draft in the official languages of their respective countries or were originally written in English. This is the case with examples One (King Birendra, 1989), Three (Ali Khamenei, 2012) and Five (Vladimir Putin, 2018). The fourth example shows Donald Trump speaking in his native English in 2017 while the 2005 statement by Emir of Qatar is known to have been translated semi-officially by G77 officials. Now, let us scrutinize the opening salutations in these examples.

Example 1: The address by His Majesty Birendra Bir Bikram Shah Dev, King of Nepal, Ninth Non-Aligned Movement (NAM) Summit, 4-7 September 1989, Belgrade, Former Yugoslavia.

“Mr. Chairman, Your Majesties, Excellencies, Distinguished Delegates.”

The salutation above follows diplomatic etiquette in that the chairman of such international gatherings is to be addressed first, though official protocol then leaves it up to the speaker's discretion whether to proceed by naming the leader of the host nation separately, or else to include him or her within a list of attendees in descending order of rank. Even in the twenty first century, Royal attendees receive the first mention, under the assumption that such individuals have the highest rank under international diplomatic protocol. Thus, the late king of Nepal addressed these individuals present separately as "Your Majesties." King Birendra then goes on to subsume references to other top-level dignitaries such as ministers or ambassadors under the label of "Excellencies," before addressing all others in the audience directly as "distinguished delegates." 
Example 2: The address by His Highness Sheik Hamad Bin Khalifa Al-Than, Emir of State of Qatar, Second South Summit of Group of 77 and China, 12 June 2005, Doha, Qatar.

"Your Majesties, Excellencies, and Highness, H.E. The Prime Minister of Jamaica and Chairman of the Group of 77 and China, H.E. The Prime Minister of Malaysia, Chairman of the Non-Aligned Movement, Honorable Audience, AssalamuAlaikum Warahmatullah Wabarakatuh.

I welcome you all to Doha and would like to thank H.E. Mr. Percival James Patterson, the Prime Minister of Jamaica...[.....], I must also thank H.E. Mr. Abdullah Bin Ahmad Badawi, the Prime Minister of Malaysia and Chairman of Non-Aligned Movement."

The salutation above shows the sovereigns are addressed with the highest priority, followed by other heads of states, and a prince in attendance. Emir Al-Thani then salutes the prime minister of Jamaica as chairperson of Group of 77 and China, followed by the prime minister of Malaysia as chairperson of Non-Aligned Movement. Finally, all others are greeted as "honorable audience". The emir used AssalamuAlaikum Warahmatullah Wabarakatuh (May peace be upon you) equivalent of "Good morning/afternoon/evening" or "Namaste", which can be seen as a preservation of his country's religious and cultural identity. To say a few words in one's own language, the language of the host nation or that of the majority of the delegates is often done to create a friendly atmosphere. The example mentioned above strictly adheres to established norms and supports the protocol of precedence in the diplomatic world.

Example 3: The address by Sayyid Ali Hosseini Khamenei, the supreme leader of Islamic Republic of Iran, Sixteenth Non-Aligned Movement (NAM), August 30, 2012, Teheran, Iran.

"In the Name of Allah, the Beneficent, the Merciful.

All praise belongs to Allah, the Lord of the Two Worlds, and may peace and blessings be upon the greatest and trustworthy Messenger and on his pure progeny, his select companions, and all the prophets and divine envoys.

I welcome you honorable guests, the leaders, and delegations representing the member states of the Non-Aligned Movement, and all the other participants of this high international summit." 
In example 3, we can see that the first priority is given to Allah, as is usual in the Muslim world, and this is accepted with regard to Islamic nations throughout the world since it is a cultural norm. Ali Khamenei, right after praising Allah, welcomes royalty and heads of states collectively as "honorable guests" and "leaders" before finally addressing everyone else rather impersonally as "delegations" (rather than as "delegates") of the NAM member states.

Khamenei, as the highest-ranked leader of Islamic Republic of Iran and in his world view, on par with the royalty of the world, seems to be ignoring other royalties. For this reason, his salutation cannot be regarded as following the protocol of international diplomacy. Due to the nature of the somewhat authoritarian state he represents, Khamenei may have seen himself just below the prophet, thus outranking all other participants.

Example 4: The address by President of the United States of America, Donald Trump, ArabIslamic American Summit, 20-21 May 2017, Riyadh, Saudi Arab.

"I want to thank King Salman for his extraordinary words, and the magnificent Kingdom of Saudi Arabia for hosting today's summit [......], Let me now also extend my deep and heartfelt gratitude to each and every one of the distinguished heads of state who made this journey here today."

Addressing the Arab-Islamic summit in 2017, Donald Trump explicitly addresses the king of Saudi Arabia, after which he subsumes all the other kings, princes, presidents, prime ministers etc. as "distinguished heads of states". It is noteworthy that he does not greet anyone else in the audience. Though the American president praised Saudi Arabia and its king as the host nation, he did not follow standard protocol by using the term "Your Majesties". Given the presence of the king of Bahrain, the king of Jordan, the sultan of Brunei and the ruling prince of the United Arab Emirates, this was a noticeable omission.

Example 5: The address by President of Russia, Vladimir Putin, 25-27 July 2018, Tenth Brazil, Russia, India, China, South Africa (BRICS) Summit, Johannesburg, South Africa. 
"Mr President Ramaphosa, President Xi Jinping, President Temer, Prime Minister Modi, Colleagues."

The Russian President in his opening address of the BRICS summit in 2016 first acknowledges the president of the host nation, South Africa, as "Mr. President", then mentions the names of each president or prime minister in attendance. All other delegates are then subsumed under the label of "colleagues". Due to the limited number of participant countries, Putin was able to address the names of each head of state present. The order of the names should be noted, though Putin initially addresses the president of South Africa out of consideration for that nation being the host nation of the summit. He then goes on by mentioning the leaders of China, Brazil and India. As we can see that the order of the salutation was not made alphabetically, power and relationship might play a factor while choosing the order of salutation.

In communist countries, it has been customary to officially view everyone as equal by saying "comrade" instead of using official position titles. Though Russia is not a communist country anymore, President Putin's use of "colleagues" might imply that the residues of communist and military ideology are still abundant. This thesis might be supported by referring to Putin's early career in the Soviet Union, when he was an officer of the Committee for State Security (KGB).

\section{Conclusion}

This paper has focused on the language used in the opening salutations of summit speeches and their role in international diplomacy. These salutations are an indispensable part of every such speech. Regardless of the content, opening salutations are mostly identical in form at every kind of summit. Royalties are traditionally addressed first, followed by other heads of state, princes, heads of government, ministers and other attendees. As a courtesy to the host nation, it seems to be a matter of speaker's discretion whether to address the host nation first. It was found that the standard protocol is still essentially unchanged from what it was 30 years ago. The character of the leader making the address along with the religion, and, possibly, the ideology (s)he adheres to, also play an essential role in how official salutations are crafted. Furthermore, the unwritten conventions of diplomatic protocol can be seen as remaining an effective and largely followed guideline in determining salutations in the context of international diplomacy, where the function of salutations is to show respect to those attending such events. 
Surendra Pokhrel / Diplomatic Language: An Analysis of Salutations ... Vol. 3, 180-193, 2020

Surendra Pokhrel (suru.pokhrell@gmail.com) got his M.A. in International Administration at Josai International University, Tokyo, Japan, in 2016. Currently, he is a Ph.D. candidate at the Graduate School of Foreign Languages, Daito Bunka University, Tokyo, Japan.

\section{References}

Afrin, O. (2010). Langue Diplomatique et Langage Formel: Un Code à Double Entente, Hermès: La Revue Cognition, communication, politique, 58(3), 71-77.

Azizan, M. N. A. (2018). THE TRUE DEFINITION OF SUMMIT MEETING. Journal of Humanities, Language, Culture \& Business, 2(8), 106-113.

Kuanish, B., Spang, C.W., \& Tussupov, N. (2011). Civilizations in International Relations: Huntington's Theory of Conflict, Outside the Box: The Tsukuba Multi-Lingual Forum, 4(1), 24-31.

Bowers, J. W., \& James J.B. (1984). Contemporary problems in human communication theory. In Carroll C. Arnold and John Waite Bowers (eds), Handbook of Rhetorical and Communication Theory. Boston: Allyn and Bacon, 872-874.

Burhanudeen, H. (2006). Diplomatic language: An insight from speeches used in international diplomacy. Akademika (67), 37-51.

Carmody, D.P., \& Lewis M. (2006). Brain activation when hearing one's name and other's name. Brain Research. 1116 (1), 153-158.

Girardin, B. (2001). Language settings at the stage. In Jovan Kurbalija and Hannah Savik (eds) Language and Diplomacy, Malta: Mediterranean Academy of Diplomatic Studies, 139152.

Grice, H. P. (1975). Logic and conversation. In P. Cole and J.L. Morgan (eds), Syntax and Semantics, Vol. III. Speech Acts. New York: Academic Press, 41-58.

Heerwegh, D. (2005). Effects of Personal Salutations in E-mail Invitations to Participate in a Web Survey. Public Opinion Quarterly, 69(4), 588-598.

Jaber, K.S.A. (2001) Language and Diplomacy. In Jovan Kurbalija and Hannah Savik (eds) Language and Diplomacy, Malta: Mediterranean Academy of Diplomatic Studies, 4954.

Kealey, D.J., MacDonald, D., \& Vulpe, T. (2004). Intercultural competence and its relevance 
for international diplomacy. In H. Slavik (ed.), Intercultural Communication and Diplomacy. Geneva: Diplo Foundation, 431-444.

Kealey, D.J. (1996), Interpersonal and Cultural Dimensions of Canadian Development Assistance in Egypt. Hull, Quebec: Canadian International Development Agency.

Krauss, R. M., \& Chiu, C. Y. (1998). Language and social behavior. In Gilbert D.T., Fiske S.T., \& Lindzey G.(eds.), The handbook of social psychology. McGraw-Hill, 41-88.

Matos, F. G. (2004). Applying the Pedagogy of Positiveness to diplomatic communication, In Jovan Kurbalija and Hannah Savik (eds) Language and Diplomacy, Malta: Mediterranean Academy of Diplomatic Studies, 281-287.

Matteucci, A. (2001). Language and Diplomacy- A Practitioner's View, In Jovan Kurbalija and Hannah Savik (eds) Language and Diplomacy, Malta: Mediterranean Academy of Diplomatic Studies, 55-65.

Nick, S. (2001). Use of Language in Diplomacy, In Jovan Kurbalija and Hannah Savik (eds) Language and Diplomacy, Malta: Mediterranean Academy of Diplomatic Studies, 3947.

Pascual, E. (2001). Pragmatics in Diplomatic Exchanges, In Jovan Kurbalija and Hannah Savik (eds) Language and Diplomacy, Malta: Mediterranean Academy of Diplomatic Studies, 225-232.

Pouliot, V., \& Cornut, J. (2015). Practice theory and the study of diplomacy: a research agenda. Cooperation and Conflict, 50(3), 297-315.

Rommetveit, R. (1974). On message structure: A framework for the study of language and communication. Oxford, England: John Wiley \& Sons.

Wiseman, G. (1999). 'Polylateralism' and new modes of global dialogue. DSP Discussion Papers, No. 59 (Leicester: Centre for Study of Diplomacy).

Zhang, N. (2012). An Analysis of Vagueness on Diplomatic Language, Saarbrucken, Germany: LAP LAMBERT Academic Publishing GmBH and Co. KG.

\section{Interviews:}

Interview with the Honorable Foreign Minister of Federal Democratic Republic of Nepal, Mr. Pradip Kumar Gyawali, 16 March 2019, Ministry of Foreign Affairs, Singha Durbar Kathmandu, Nepal. 


\section{Speeches:}

Speech by His Majesty Birendra Bir Bikram Shah Dev, King of Nepal at the Ninth Non-Aligned Movement Summit, 4-7 September 1989, Belgrade, Yugoslavia.

Speech by His Highness Sheik Hamad Bin Khalifa Al-Thani, Emir of the State of Qatar at the Second South Summit of the Group 77 and China, 12 June 2005, Doha, Qatar.

Speech by Sayyid Ali Hosseini Khamenei, The Supreme Leader of Islamic Republic of Iran at the Sixteenth Non-Aligned Movement Summit, 30 August 2012, Teheran, Iran.

Speech by Donald Trump, President of the United States of America at the Arab Islamic American Summit, 20-21 May 2017, Riyadh, Saudi Arabia.

Speech by Vladimir Putin, President of Russian Federation at the Tenth Brazil, Russia, India, China, South Africa (BRICS) summit, 25-27 July 2018, Johannesburg, South Africa.

\section{Acknowledgement}

I want to thank my academic advisor Professor Christian W. Spang, based on his expertise in the history of International Relations and comparative diplomatic history. He offered many valuable suggestions. I would like to thank Dr. Robert Sigely, Dr. Hikaru Kitabayashi and Professor Jefferey Johnson for cross-checking the manuscript. Furthermore, I am thankful to the reviewer whose comments helped me much in the process of revision of this article. 